\title{
Key technologies for extinguishing coal pillar self-heating in close distance coal seams
}

\author{
Changshan zhang1 ${ }^{2, a}$, Zhijin $\mathrm{Yu}^{1, \mathrm{~b}}$, Xinhai Zhang ${ }^{1, \mathrm{c}}$ \\ ${ }^{1}$ Energy school, Xi' an University of Science and Technology, Xi' an Shanxi 710054 China; \\ ${ }^{2}$ Heilongjiang longmay mining holding group, shuangyashan coal group, Shuangyashan \\ Heilongjiang 155100 China; \\ a254948606@qq.com, byuzj0927@163.com, c498870163@qq.com
}

Keywords: coal pillar self-heating, liquid nitrogen, polymer colloid, three-phase foam

\begin{abstract}
The coal pillar self-heating process of the 16\# coal seam, which lays above the 18\# coal seam that being mined in Dongrong 2\# coal mining was examined. The cause of upper pillar spontaneous combustion during the mining of close distance coal seams was analysed. According to the distribution characteristics of the mining areas and the gas detective result, the scope of high temperature was judged, and the main method asphyxia and cooling was determined. This included infusion of polymer colloid and three-phase foam into flame location, a wide range of gob nitrogen injection, and effective plugging measures. The results showed that these measures rapidly extinguished coal pillar self-heating, lowering the $\mathrm{CO}$ concentration from $16000 \mathrm{ppm}$ to about 10 ppm and reducing the temperature from $81^{\circ} \mathrm{C}$ to less than $20^{\circ} \mathrm{C}$ in the closed system of $16 \#$ coal seam. Illustrating that though various material of extinguishing applied, the problem of coal pillar self-heating was eliminated efficiently.
\end{abstract}

\section{Introduction}

The spontaneous combustion of coal is a worldwide disaster in the mining industry, which being led by an indispensable multi-factors environment of residual coal, air leakage and heat storage in the underground mine $[1,2]$. As Chinese complicated geological conditions and a long history of mining, the method of adjoining seam group mining is widely applied [3]. And the hazards of spontaneous combustion of neighboring coal seam in the old mining areas that used the method is serious especially. Dongrong 2\# coal mining located in the province of Hei Long Jiang in the northeast of china, is an underground coal mine with three working coal seams of $16 \#, 17 \#$ and $18 \#$. The average interlayer spacing upper to lower are $15 \mathrm{~m}$ and $18 \mathrm{~m}$, composing a typical adjoining seam group. During the repeated exploiting process, the layered coal seam collapse for several times, crushing seriously. Which result to numerous inter laminar fractures and cause the leakage of air flow. It is easily to occur the spontaneous combustion for the coal laid in the overlying enclosed space when the lower coal seam is exploited $[4,5]$. While the high pressure in the closed burring area lead the leakage of $\mathrm{CO}$ and other hazardous gases, threatening mine production and the workers' safety. The concentration of $\mathrm{CO}$ in the enclosed space of $16 \#$ and $17 \#$ coal seam was detected to increase From June 242010 with a significantly increased trend. During the continuous observation of ten days it reached the peak concentration of 16000 PPM. And the characteristic gases of coal combustion like $\mathrm{C}_{2} \mathrm{H}_{4}, \mathrm{C}_{2} \mathrm{H}_{2}$, etc. were also be detected, indicating an obvious portent of coal spontaneous combustion. Clearly, for inhibiting the trend of self-heating, a more positive and effective fire control technology was urgently needed.

This paper takes the Dongrong 2\# coal mining fire as a typical case. By analyzing the characteristics and causes of coal pillar self-heating in close distance coal seams, a set of efficient fire prevention and extinguishing techniques is proposed and practiced. 


\section{Methods and scheme}

\subsection{Determine the ignition position}

The results at $\mathrm{CO}$ concentration rising position showed that, on July $2 \mathrm{CO}$ concentration at fire seal (692) of 16\# coal seam 9 working face (16\#-9F) return airway was 485 ppm, 61 ppm at fire seal (6101) of 16\#-10F intake airflow roadway, and $1041 \mathrm{ppm}$ at fire seal (781) of 17\#-8F intake airflow roadway. On July 7 the corresponding CO data was 692 (5237 ppm), 6101 (5901 ppm), 781(469 ppm).

What's more, during the process of 6101\# fire seal unsealing, obtaining the CO data was 8000 ppm, The roof temperature was $60^{\circ} \mathrm{C}$, the air temperature was $38^{\circ} \mathrm{C}$ at $30 \mathrm{~m}$ distance from fire seal. Meanwhile, On August 6 the result of drill hole showed the CO of 16000 ppm at 6101\# fire seal. At the moment, there was not an obvious rise on $\mathrm{CO}$ concentration at upper corner of $18 \#-7 \mathrm{~F}$.

On the layout, two 20 meters wide coal pillars one was located between $16 \#-9 \mathrm{~F}$ and $16 \#-10 \mathrm{~F}$, another was located between $17 \#-7 \mathrm{~F}$ and $17 \#-8 \mathrm{~F}$ were above the $18 \#-7 \mathrm{~F}$. All the upper working face had been sealed. Figure 1 represents the position relationship between the working face.

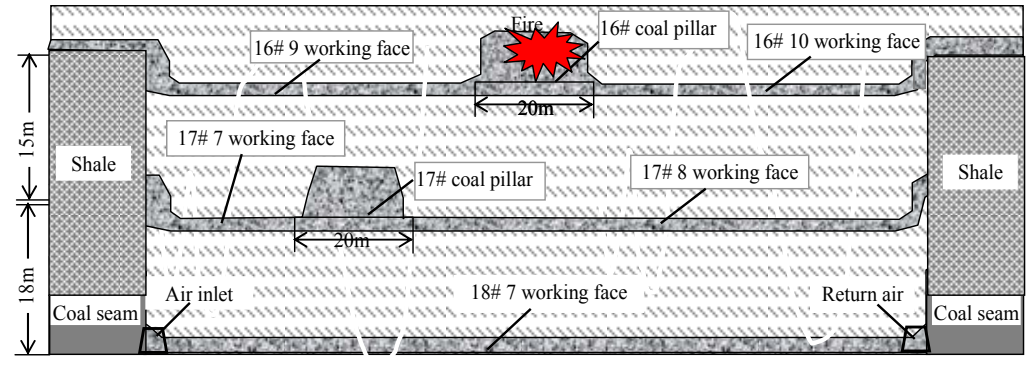

Fig. 1 The cross-section profile of working face in close distance coal seams

$16 \#$ coal seam was stop mining in advance due to the impact of fault, the stopping line was located above the gob of $17 \#$ and $18 \#$ coal seam. When the lower coal seam was mining there must be air leakage to $16 \#$ coal seam stopping line, and resulting in self-heating of $16 \#$ coal seam coal pillar.

In summary, the ignition position lied in the pillar between $16 \#-9 \mathrm{~F}$ and $16 \#-10 \mathrm{~F}$, and located above the 18\#-7F $500 \mathrm{~m}$ from working face. The pillar was in a smoldering state.

\subsection{Analysis of causes of coal fire}

The reasons for the coal pillar self-heating were as follows:

1) Serious air leakage and repeated oxidation, the distance of close coal seam was small, there existed a lot of air leakage channel, which leading to high concentration of oxygen around 16\# coal pillar, and providing a favorable condition for the oxidation of coal. At the same time, the spontaneous combustion period of $16 \#$ coal pillar significantly shortened after repeated oxidation in the mining process of $16 \#, 17 \#$, and $18 \#$ coal seam $[6,7]$.

2) A large and broken abandoned coal, there was a $20 \mathrm{~m}$ wide, about 11,000 tons of coal pillar remained in the gob of $16 \#$ coal seam. The coal was subjected to the impact of two mining, in consequence crushing serious, which accelerated the reaction rate of coal oxidation [8], and calorific value increased greatly in unit time.

3) Heat dissipation in enclosed space was weak, 16\# coal seam closed space was away from the source of air leakage, air flowing slowly, forming a good heat accumulated environment, resulting in rapid pillar temperature rising.

\section{Key technologies for extinguishing coal pillar self-heating}

\subsection{Plugging air leakage channel}

Various artificial methods were used to reduce air leakage to $16 \#$ coal seam pillar between $16 \#-9 \mathrm{~F}$ and 16\#-10F. Specific measures were depicted in table1: 
Table 1 Specific measures of plugging air leakage

\begin{tabular}{ccc}
\hline Position & Material & Method \\
\hline $18 \#-7 \mathrm{~F}$ & & Reduce blowing rate and pressure balancing \\
691\#、692\#、6101\#、6102\# & Luokexiu foam、 & Plugging and strengthen in top and each sides \\
fire seals in 16\# coal seam & cement mortar & Reinforce \\
772\#、762\#、781\#、782\# & $\begin{array}{c}\text { Polyethylene } \\
\text { fire seals in 17\# coal seam }\end{array}$ & imine resin \\
\hline
\end{tabular}

\subsection{Injecting liquid nitrogen}

The temperature of liquid nitrogen is $-195.8^{\circ} \mathrm{C}$, and its latent heat of vaporisation is $199 \mathrm{~kJ} / \mathrm{kg}$. Liquid nitrogen quickly evaporates into gaseous nitrogen at a temperature of $-193^{\circ} \mathrm{C}$; one tonne of liquid nitrogen forms $780 \mathrm{~m}^{3}$ of nitrogen gas. Thus liquid nitrogen absorbs more heat-in other words, has a greater cooling effect - than nitrogen gas [9].

To rapidly reduce the temperature of the spontaneous combustion of coal pillar, displace the harmful gases, and inhibit the fire development. From 20 August 2010, liquid nitrogen was poured into the 6101\# fire seal through a system of injecting nitrogen continuously. The liquid nitrogen system consisted mainly of a moveable storage tank containing liquid nitrogen, a cryogenic centrifugal pump, and stainless steel pipeline. The flow rate was set as no less than $800 \mathrm{~m}^{\wedge} / \mathrm{h}$.

\subsection{Injecting three-phase foam and polymer colloid}

For the position of self- ignite coal pillar, the special fire prevention tunnel is excavated along the $16 \#$ and $18 \#$ coal seam apart. The tunnel of $16 \#$ coal seam is 170 meters long, its end close to the zone of ignition coal pillar. Construct fire prevention drill hole above the 16\# coal pillar though the tunnel. There are 16 drill holes in total and the accumulative drilling length is 450 meters. The tunnel of $18 \#$ coal seam is 190 meters long, the length is 287 meters in all. 10 drill holes are constructed toward the fire zone. The layout of drill holes is shown in figure 2

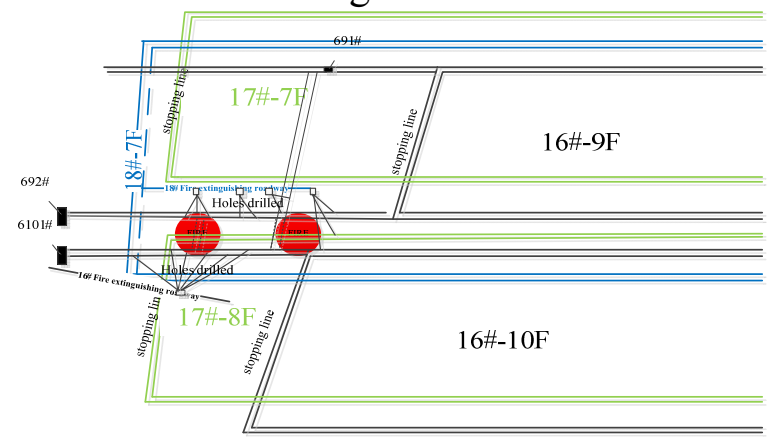

Fig. 2 the layout of drill holes for extinguishing self-ignite coal pillar

Injection is two stages. First, to achieve the purpose of extinguish fire area. The three-phase foam which has a characteristic of high expansion ratio, wide coverage, a long stability time is used to cool and cover the high temperature coal [10].

Figure 3 shows the pouring technique of the three-phase foam. First, foaming agent and retardant at a given ratio into the slurry of yellow mud or fly ash were added into a metering pump; then, compressed air is mixed with the slurry, producing large volume of foam; finally, the foam is injected into the fire zone via a delivery hose and drill holes.

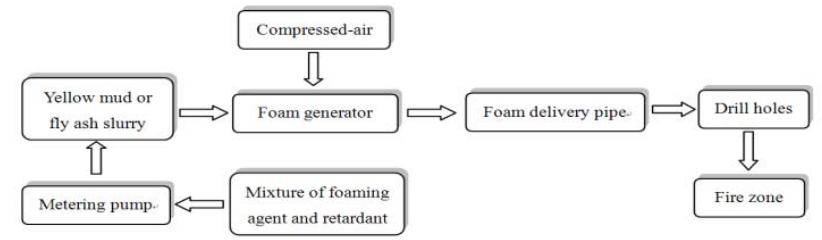

Fig. 3 Flow chart of the foam inhibitor preparation and injection process

Between 8 August and 30 November 2010, a total of 26 tonnes of three-phase foam was injected near the spontaneous combustion of coal pillar though 26 holes drilled circularly. 
Second stage, polymer colloid which has an advantage of a better heap and filling effect and a long-term and stable solid form is applied to fill the self-ignite coal pillar and gob in order to ensure that fire extinguishing effect after the temperature and $\mathrm{CO}$ gas concentration falling down.

Between 5 December 2010 and 11 March 2011, 20 tonnes polymer colloid was injected into the fire prevention and extinguishing area by 26 holes drilled circularly.

\section{Results and discussion}

On the initial phase of injecting three-phase foam, there was plenty of vapor gushed from 6101\# fire seal, and the surface temperature reached $81^{\circ} \mathrm{C}$, meanwhile, $\mathrm{CO}$ concentration increased to 200 ppm at 692\# fire seal and vapor gushed. Two days later, the phenomenon was eliminated. The above indicated that the three-phase foam injected by drill holes contacted with high temperature coal, and produced a large amount of water vapor and CO immediately. Figure 4 shows the change of index gases during the whole process.
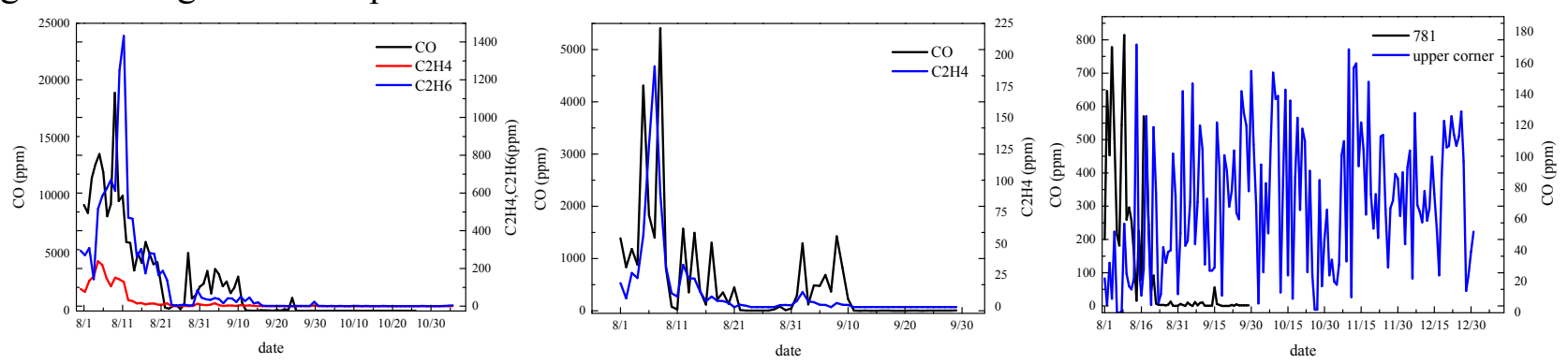

Fig .4 The change of index gases at various position; a) index gases data at 30m from 6101\# fire seal; b) index gases data at 691 \# fire seal; c) CO concentration at upper corner of $18 \#-7 \mathrm{~F}$ and 781 \# fire seal, respectively

Seen from Figure $4 \mathrm{a}$ and $4 \mathrm{~b}$, the gas concentration of $\mathrm{CO}, \mathrm{C} 2 \mathrm{H} 4, \mathrm{C} 2 \mathrm{H} 6$ was significantly decreased at $30 \mathrm{~m}$ from $6101 \#$ and $691 \#$ fire seal after the measures be implemented. CO concentration gradual declined from the highest $18000 \mathrm{ppm}$ and $5500 \mathrm{ppm}$ respectively. On September 15, CO concentration was $29 \mathrm{ppm}$ and $2 \mathrm{ppm}$ at the two places, then keep in a low concentration for a long time. The acetylene $(\mathrm{C} 2 \mathrm{H} 4)$ concentration remained steady at $0 \mathrm{ppm}$ and the concentration of ethylene $(\mathrm{C} 2 \mathrm{H} 6)$ remained steady at $0-2 \mathrm{ppm}$.

It illustrated the judgment of the self-ignite position was very accurate in early, and fire prevention materials were applied in key position efficiently. In figure 4c, an apparent decline of $\mathrm{CO}$ concentration at $781 \#$ fire seal was earlier than it at the upper fire seal of $16 \#$ coal seam, which meant the increased $\mathrm{CO}$ at $17 \#$ coal seam was main from the oxidation of $16 \#$ coal seam pillar. But there was not a spontaneous combustion omen occurred at $17 \#$ coal seam.

From figure $4 \mathrm{c}$, during the whole process of spontaneous combustion and government, the $\mathrm{CO}$ concentration at upper corner was in 0-160 ppm. It stated the upper corner $\mathrm{CO}$ of mining working face could not make an effective prediction of coal spontaneous combustion for the upper coal in close distance coal seams.

Via 7 months comprehensive treatment, until finishing the whole mining work of $18 \#-7 \mathrm{~F}$, the index gas was remained steady at each monitoring points. This indicated nitrogen, three-phase foam, polymer colloid material had effectively extinguished coal pillar self-heating in close distance coal seams.

\section{Conclusion}

The upper residual coal in close distance coal seams has a characteristic of better heat storage and oxygen surroundings, more broken coal, and a shorter spontaneous combustion period, these conditions are highly prone to spontaneous combustion ignition and re-ignition. Due to the hidden ignition position, it is hard to apply fire-fighting material to the effective spot. 
Basing on the change of index gas at each measuring points, the location of fire position is determined. A series of effective measures, including plugging air leakage channel, injecting liquid nitrogen, polymer colloid and three-phase foam are applied to extinguish the coal pillar self-heating of $16 \#$ coal seam.

When low-temperature liquid nitrogen is injected into burning area, it will reduce the temperature and oxygen concentration around the coal pillar dramatically, and an apparent asphyxiant effect. Three-phase foam can complete the cooling and inhibition for spontaneous combustion of coal pillar. Polymer colloid has been used to fill the gap of loose coal, and preventing oxidation and re-ignition for a long time. The results of index gas changing show that these fire prevention materials make it highly suitable for controlling fires occupying in coal pillar and/or hidden fires, and for preventing spontaneous combustion re-ignition.

\section{References}

[1]. Carras JN, Day SJ, Saghafi A, etc. Greenhouse gas emissions from low-temperature oxidation and spontaneous combustion at open-cut coal mines in Australia. Int J Coal Geol, 78 (2009) 161-168.

[2]. Ze yang Song, Claudia Kuenzer. Coal fires in China over the last decade: a comprehensive review. Int J Coal Geol, 133 (2014) 72-99.

[3]. B.T .Qin, Y. Lu, S.J. Yin, etc. Prevention and control technique of complex disaster caused by gas and spontaneous combustion for fully-mechanized sublevel caving face in close-distance seams [J]. Journal of Mining and Safety Engineering, 30 (2) (2013) 311-316.

[4]. G.W. Fan, D.S. Zhang, L.Q. Ma. Overburden movement and fracture distribution induced by long-wall mining of the shallow coal seam in the Shen-Dong coalfield [J]. Journal of china University of Mining and Techology, 40 (2) (2011) 196-201.

[5]. T.X. Chu, M.G. Yu, S.Q. Yang, etc. Air leak induced by well developed coal fractures and prevention of spontaneous combustion in goaf [J]. Journal of Mining and Safety Engineering, , 27 (1) (2010) 87-91.

[6]. Jun, Deng, Jingyu, Zhao, Yanni, Zhang, etc. Study on Coal spontaneous combustion characteristic temperature of growth rate analysis. Procedia Engineering, 84 (2014) 796-805.

[7]. Jun Deng, Yang Xiao, Qingwei Li, etc. Experimental studies of spontaneous combustion and anaerobic cooling of coal. Fuel, 157(2015) 261-269.

[8]. Wen, Hu. (2003). Study on experimental and numerical simulation of coal self-ignition process. Xi' an University of Science \& Technology china ( $\mathrm{PhD}$ Thesis).

[9]. Yuan, Z. and Wan, L. Application of liquid nitrogen system to control fire in coal mine. Coal Engineering, 3 (2013) 45-49.

[10]. Botao Qin, Yi Lu, Yong Li, etc. Aqueous three-phase foam supported by fly ash for coal spontaneous combustion prevention and control. Advanced Powder Technology, 25 (2014) 1527-1533. 